\title{
Twenty-Year Follow-Up of Excimer Laser Photorefractive Keratectomy: A Retrospective Observational Study
}

\author{
Giovanni Cennamo · Feliciana Menna · Fabrizio Sinisi • \\ Gilda Cennamo - Maria Angelica Breve - Pasquale Napolitano • \\ Maddalena De Bernardo · Livio Vitiello · Nicola Rosa (D)
}

Received: May 17, 2020 / Published online: July 28, 2020

(C) The Author(s) 2020

\section{ABSTRACT}

Introduction: Photorefractive keratectomy (PRK) was introduced in the late 1980s to correct myopia. The purpose of this study was to assess its long-term efficacy and safety, analyzing patients with at least 20-year follow-up.

Methods: This retrospective observational study was carried out on 85 eyes of 54 patients (33 females) that underwent PRK between 1991 and 1998 (mean age $32.62 \pm 9.74$, range $18-55$ years). Both preoperatively and postoperatively, patients underwent a complete ophthalmological evaluation, including uncorrected and corrected distance visual acuity, slitlamp, intraocular pressure, dilated fundus, and corneal topographic examinations. The outcome assessment was made by comparing the preoperative refraction, as spherical equivalent, with the postoperative ones, taking into account the planned refractive correction.

Digital Features To view digital features for this article go to https://doi.org/10.6084/m9.figshare.12619913.

G. Cennamo - F. Menna · F. Sinisi - G. Cennamo

M. A. Breve · P. Napolitano

Head and Neck Department, University of Naples

"Federico II", Naples, Italy

M. De Bernardo $\cdot$ L. Vitiello · N. Rosa $(\bowtie)$

Department of Medicine, Surgery and Dentistry,

"Scuola Medica Salernitana", University of Salerno, Baronissi, Salerno, Italy

e-mail:nrosa@unisa.it
Safety and efficacy indices were also calculated. All the data were evaluated with a paired $t$ test. Results: The mean attempted correction as spherical equivalent was $-5.64 \pm 3.01 \mathrm{D}$ (range -1.00 to $-15.00 \mathrm{D}$ ), while the mean achieved correction after 20 years was $-4.30 \pm 3.13 \mathrm{D}$ (range -1.88 to $-14.25 \mathrm{D})$, with a significant statistical difference $(p<0.01)$.The mean expected refractive outcome was $-0.27 \pm 0.81 \mathrm{D}$ (range -4.00 to $+1.25 \mathrm{D})$. The mean difference between achieved and attempted treatment was $1.33 \pm 1.92 \mathrm{D}$ (range -4.25 to $+6.25 \mathrm{D}$ ), with a significant difference $(p<0.01)$. The safety index was 1.00 and the efficacy index was 0.63 .

Conclusion: The results provided by this study highlight that the procedure could be considered safe, with no long-term sight-threatening complications such as late ectasia or haze.

Keywords: Long-term follow-up; Myopia; Photorefractive keratectomy; PRK 


\section{Key Summary Points}

\section{Why carry out this study?}

Since the late 1980s photorefractive keratectomy (PRK) has been widely used to correct myopia.

The purpose of this study was to assess long-term efficacy and safety of PRK, analyzing patients with at least 20 -year follow-up.

\section{What was learned from the study?}

PRK could be considered a safe and effective procedure even with old devices.

Following the correct indications, no longterm sight-threatening complications such as late ectasia or haze after PRK have been detected.

\section{INTRODUCTION}

Photorefractive keratectomy (PRK) using an excimer laser was introduced in the late 1980s to correct myopia and was mainly utilized to treat low to moderate myopia [1-6]. Few studies have dealt with the correction of high myopia, because earlier attempts had been associated with regression, undercorrection, and corneal haze $[1,2,7]$.

It is very important to assess the long-term efficacy and safety of every type of medical or surgical procedure. A literature review within the PubMed medical database detected several papers that reported long-term follow-up of patients that underwent PRK [8-17], but only one reported a 20-year follow-up [18]. For this reason, the purpose of this study was to evaluate the results obtained in patients that underwent PRK before 1998. 
that initiated treatments with a diameter of $5 \mathrm{~mm}$ and progressively closed, producing a flattening of the central cornea. Afterwards, a new mask was manufactured with an iris diaphragm that starts from $6 \mathrm{~mm}$ in diameter for treatments less than 6.5 diopters (D) and $7 \mathrm{~mm}$ in diameter for higher treatments in which, in addition to the standard Munnerlyn algorithm used centrally, a tapered transition zone (TTZ) outside this area was used $[19,20]$.

Most of the patients had unilateral myopia, whereas those with a bilateral defect were treated at least 2 months apart.

At the end of all surgical procedures, preservative-free gentamycin eye drops were applied and the eye was patched. The same eye drops were administered four times daily until re-epithelialization was complete, and neither mitomycin nor corticosteroid eye drops were used.

No enhancement was performed in these patients.

\section{Outcome Assessment}

Patients who presented with a minimum follow-up of 20 years were recruited in the study. They underwent a complete ophthalmological evaluation, including UDVA and CDVA, slitlamp examination, intraocular pressure evaluation, dilated fundus examination, and corneal topographic examination to look for signs of ectasia.

The comparison between the preoperative refraction as SE and the postoperative ones was evaluated taking into account the planned refractive correction, namely subtracting the eventual planned hypo- or hypercorrection from the final refraction. The safety and efficacy indices were also measured. The safety index was described as postoperative CDVA divided by preoperative CDVA (CDVA post/CDVA pre), while the efficacy index was expressed as postoperative UDVA divided by preoperative CDVA (UDVA post/CDVA pre).

\section{Statistical Analysis}

All data were entered into a Microsoft Excel spreadsheet; mean, standard deviation, maximum, and minimum values for each parameter set were calculated. The Student paired $t$ test was used to calculate the level of statistical significance and $p$ values less than 0.01 were considered statistically significant.

\section{RESULTS}

Among the treated patients, most of them were not able to be reached because they changed their address or telephone number, 57 died, and 302 refused to come for the examination. For this reason, 66 patients (101 eyes) were examined. Among these, 11 eyes underwent cataract surgery and two had retinal detachment and so were excluded from the refractive evaluation. Moreover, only three eyes (two patients) were treated with the first mask, and they were also excluded. So, in the end, 85 eyes of 54 patients (33 females) were included in this study. At the time of the treatment, the mean age was $32.62 \pm 9.74$ (range 18-55 years).

The obtained results are shown in Figs. 1, 2, 3,4 , and 5 .

The mean preoperative UDVA and CDVA were $0.09 \pm 0.11$ (range 0.02-0.60) and $0.95 \pm 0.18$ (range 0.10-1.20), respectively. The mean postoperative UDVA and CDVA at 20 years were $0.60 \pm 0.44$ (range $0.02-1.50$ ) and $0.95 \pm 0.25$ (range 0.10-1.50), respectively.

The mean attempted correction as SE was $-5.64 \pm 3.01 \mathrm{D}$ (range -1.00 to $-15.00 \mathrm{D}$ ), while the mean achieved correction after 20 years was $-4.30 \pm 3.13 \mathrm{D}$ (range -1.88 to - 14.25 D), with a significant statistical difference $(p<0.01)$.

The mean expected refractive outcome was $-0.27 \pm 0.81 \mathrm{D}$ (range -4.00 to $+1.25 \mathrm{D})$. The mean difference between achieved and attempted treatment was $1.33 \pm 1.92 \mathrm{D}$ (range -4.25 to $+6.25 \mathrm{D})$, with a significant difference $(p<0.01)$. The results in terms of percentage in the different ranges of dioptric achievements are shown in Table 1, considering the mean expected refractive outcome.

The safety index was 1.00 and the efficacy index was 0.63. No patients presented with signs of corneal ectasia or haze. 


\section{Postoperative UDVA vs. Preoperative CDVA}

85 eyes, 20 years postopoperative

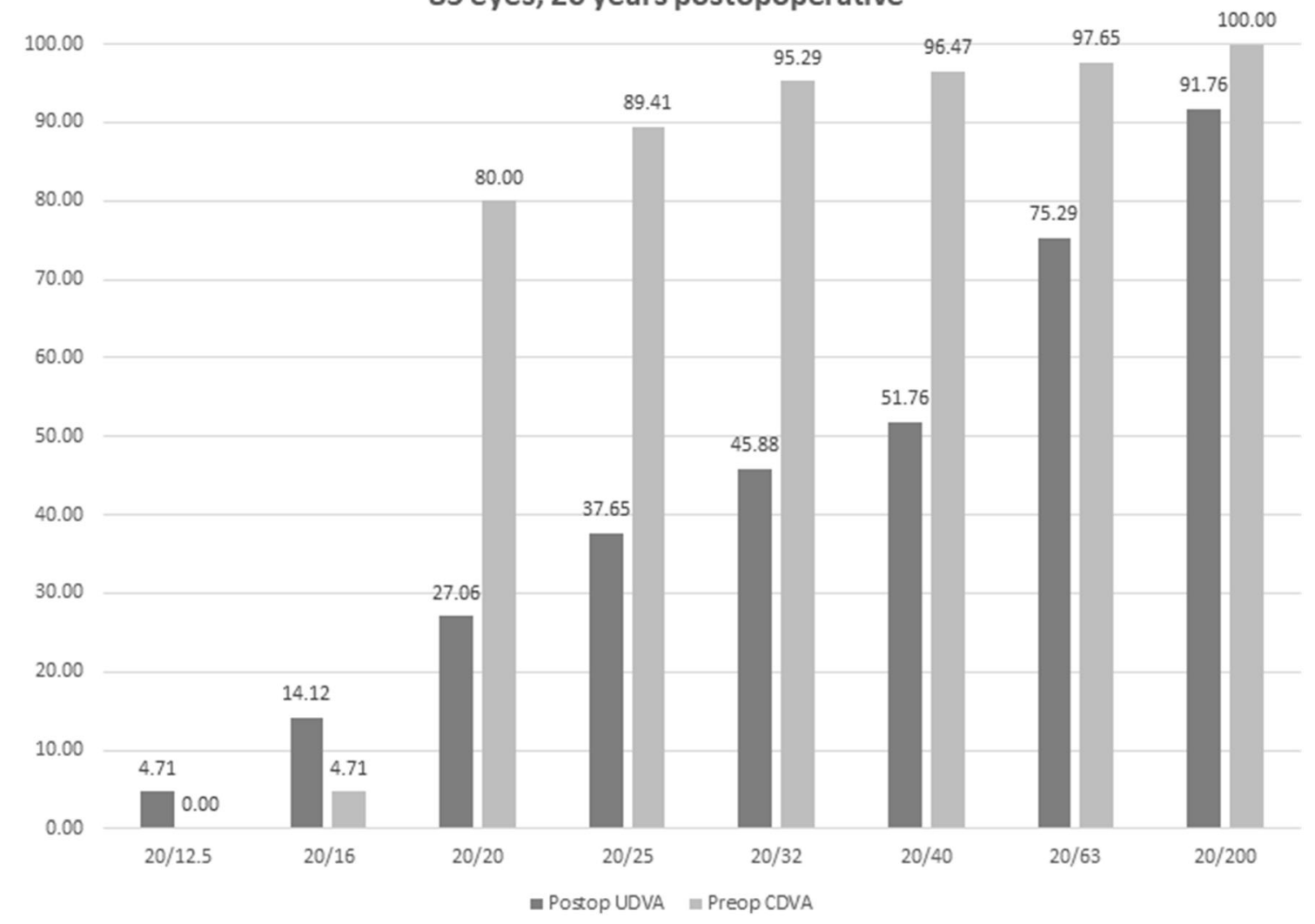

Fig. 1 Comparison between postoperative UDVA and preoperative CDVA at 20-year follow-up

\section{DISCUSSION}

It is very important to assess the long-term efficacy and safety of every type of medical or surgical technique.

When this study was planned, in the literature there were several papers that reported long-term follow-up of patients that underwent PRK [8-17], but only one reported a 20-year follow-up [18]. The main outcomes of these studies and of the present study are summarized in Table 2.

Wagh et al. [8] evaluated the long-term efficacy of hyperopic PRK in 45 eyes of 25 patients with a follow-up of 18 years. The authors found an increase in hyperopic SE refraction between 1.0 year and 7.5 years, but it was generally stable thereafter, while the efficacy was limited, with evidence of peripheral haze in $40 \%$ of cases.
Shalchi et al. [9] performed a study on 46 eyes of 46 patients with 18-year followup of excimer laser PRK, discovering a substantial increase in myopic SE, between 1 and 18 years after the procedure, in patients younger than 40 years and in women, with no long-term complications.

Vestergaard et al. [10] carried out a study on 160 eyes in patients who underwent PRK for low to high myopia, with a follow-up between 13 and 19 years. PRK for low degrees of myopia seemed safe and effective up to 19 years after surgery with conventional broad beam laser ablation, while refractive predictability was meaningfully lower and the occurrence of haze was higher in eyes with high myopia.

Lombardo et al. [11] focused on long-term changes of the anterior corneal topography after PRK for myopia and myopic astigmatism. They evaluated 66 eyes of 33 patients, with a 
Postoperative UDVA vs. Preoperative CDVA, Snellen chart lines

85 eyes, 20 years postoperative

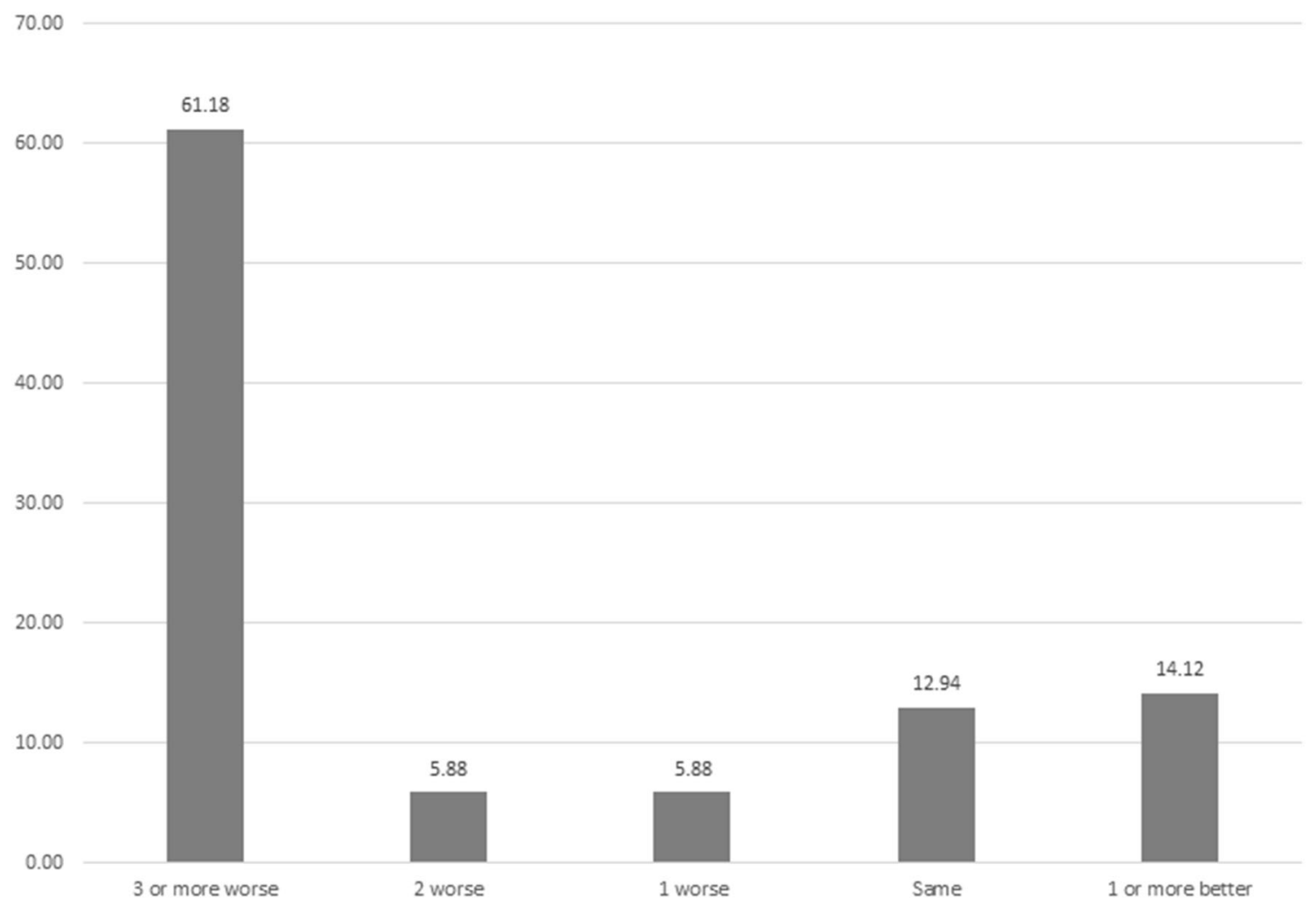

Fig. 2 Comparison between postoperative UDVA and preoperative CDVA at 20-year follow-up, considering Snellen chart lines

8-year follow-up, noticing that anterior corneal topography continues to change configuration even a long time after PRK. These modifications are limited outside the functional optical zone of the cornea, and PRK for the correction of myopia was shown not to alter the mechanical stability of the corneal tissue at 8 years after the surgical procedure.

Chen et al. [12] reviewed seven prospective studies on PRK correction for myopia involving 2796 eyes of Chinese patients, with a follow-up period of 5-11 years. This review confirmed that PRK for myopia is an effective and safe surgery for the long term in China, with efficacy and predictability which are better in low to moderate myopia than in high myopia.

Dirani et al. [13] compared PRK to laser in situ keratomileusis (LASIK), evaluating 389 eyes of 229 myopic patients, divided in two groups, with a follow-up period of $2-13$ years.
The authors demonstrated that LASIK effectively treated all levels of myopia showing better stability than PRK for up to 6-9 years.

Shojaei et al. [14] analyzed 371 myopic eyes of 203 patients to assess potential long-term complications and results of PRK, with 8-year follow-up. They ascertained the safety and the efficacy of the procedure, with stable results over time.

Aliò et al. performed two interesting studies to appraise the safety and efficacy of PRK after 10 years from the surgical procedure in 267 eyes of 191 patients with myopia of more than $-6 \mathrm{D}$ [15] and in 225 eyes of 138 patients with myopia of less than $-6 \mathrm{D}$ [16]. Both studies established the safety and efficacy of PRK, with no significant long-term complications.

Rajan et al. [17] carried out a 12-year prospective follow-up study on 68 patients to appraise the long-term refractive stability of 


\section{Change in CDVA, Snellen chart lines \\ 85 eyes, 20 years postoperative}

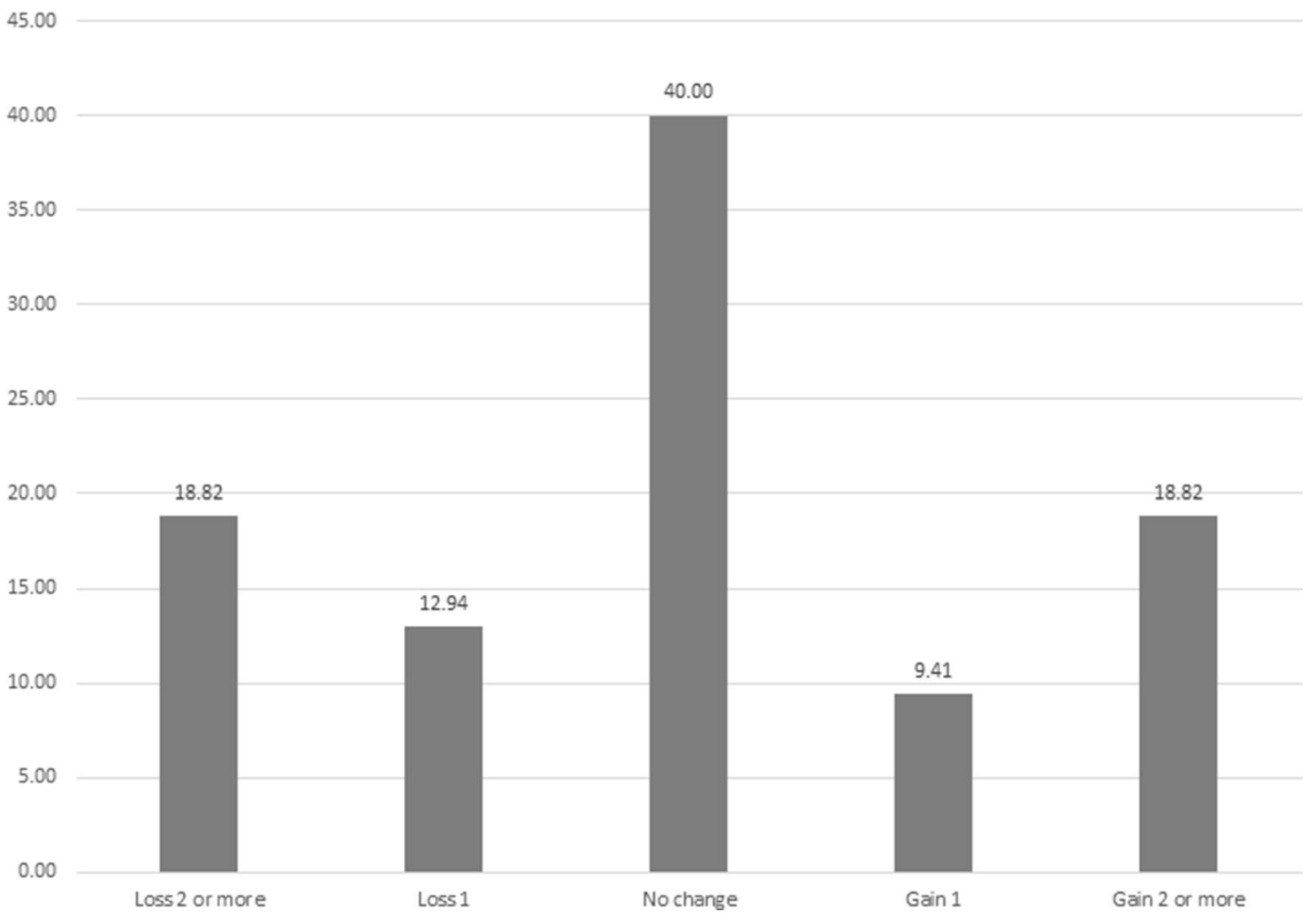

Fig. 3 Change between preoperative and postoperative CDVA at 20-year follow-up, considering Snellen chart lines

myopic PRK. The authors showed that refractive stability achieved at 1 year was maintained up to 12 years with no evidence of hyperopic shift, diurnal fluctuation, or late regression over time, while corneal haze decreased with time, with complete recovery of best spectacle-corrected visual acuity.

The results of the present study, in a larger cohort of patients, were similar to those reported in the paper by O'Brart et al. [18], the only one with a 20-year follow-up, such as this work. In fact, they reported 42 eyes of 42 patients with mean age of $58.4 \pm 10.04$ years ( 28 female and 14 male) with a mean preoperative $\mathrm{SE}$ of $-5.13 \pm 1.86 \mathrm{D}(-2.75$ to $-8.00 \mathrm{D})$. The mean postoperative SE at 1 year for all 42 eyes was $-1.18 \pm 1.35 \mathrm{D} \quad(+1.75$ to $-5.75 \mathrm{D})$. At 20 years, it was $-1.72 \pm 1.69 \mathrm{D} \quad(+1.5$ to $-4.625 \mathrm{D})$. At 20 years, the efficacy index was 0.49 and the safety index was 0.97 , both lower than those provided by the present study. These two studies prove the safety of this procedure, even if the efficacy was not so high. However, we would like to point out that in such a longterm study the ageing process could induce changes over the years, such as modifications in the lens index due to nuclear sclerosis, in the keratometric values, in the axial length (AL), and all these factors should be considered $[21,22]$.

Concerning the cataract onset, the presence of patients that underwent cataract surgery during this period could support this hypothesis.

Regarding the changes in corneal power, a study by Ivarsen and Hjortdal reported stabilization of corneal power from 1 to 7 years after PRK, but not after LASIK [23].

In our opinion, to prove changes in corneal power over 20 years is very difficult, because it is 


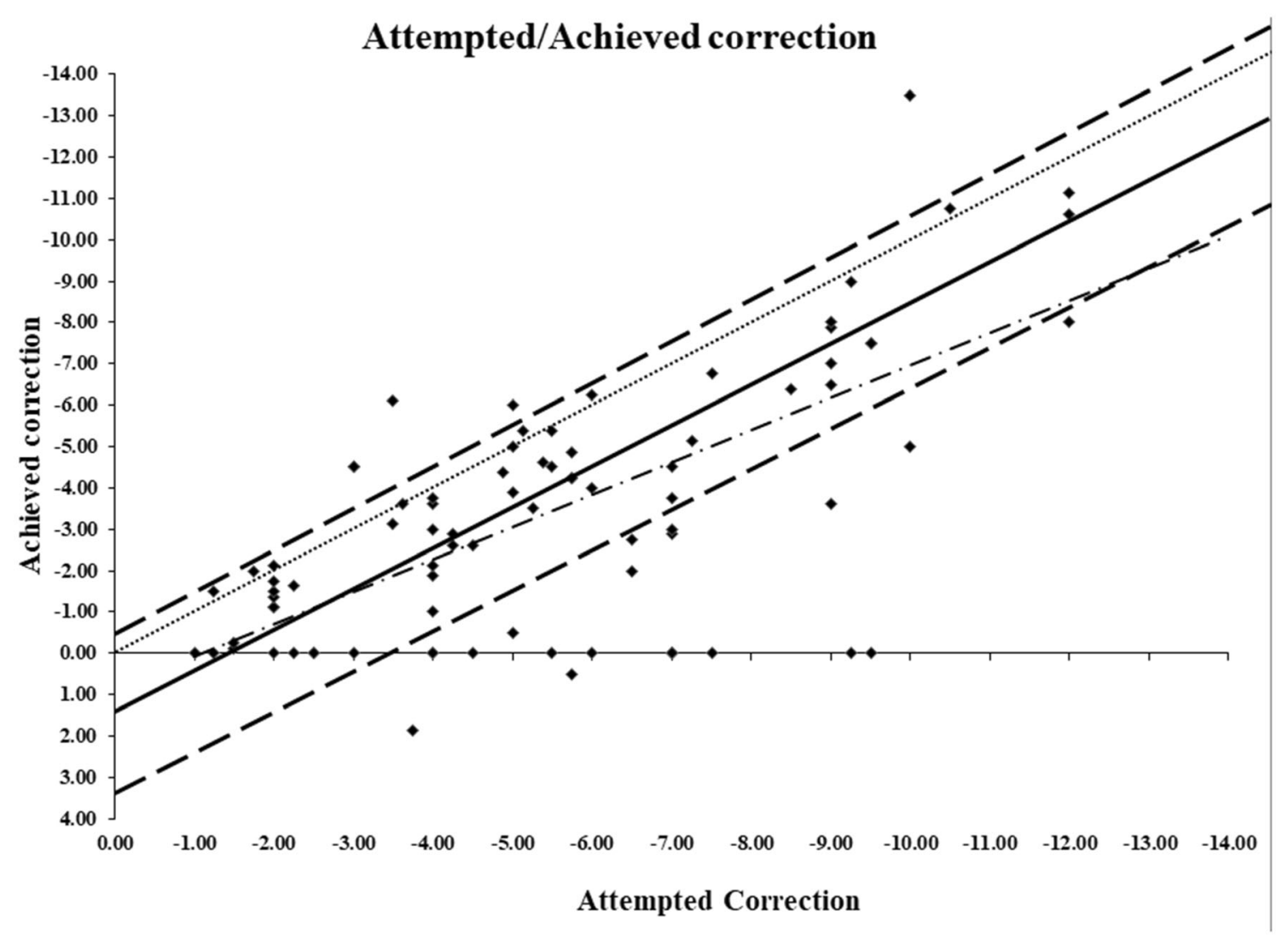

Fig. 4 Correlation between the achieved and attempted correction after 20 years. Dotted line, identity line; bold continuous line and bold dashed lines, mean \pm standard deviation; dashed-dotted line, regression line

well known that it is very challenging to measure correct corneal power in these patients, and this gives trouble when we want to calculate the intraocular lens (IOL) to be implanted after cataract surgery in these eyes. It has also been shown that different devices do not give similar results in measuring corneal power or central corneal thickness $[24,25]$. In fact, different correcting factors related to the different devices have been proposed to overcome the problem of IOL power calculation [24]. In the present study, it was impossible to make such a comparison, because the devices which were utilized in that period to measure the corneal power, such as keratometry and topography, are not available anymore.

Concerning the increase in the $\mathrm{AL}$, this has been clearly reported by O'Brart [18], who documented an increases in AL over 20 years, suggesting that myopic drift is likely to be due to continued growth of the eye, rather than to regression of correction at the corneal surface.

Changes in AL have been detected after several surgical procedures [26], but as the authors discussed in their paper, the difference they found in the AL was much more than expected. The reason could be that the preoperative measurements were taken by ultrasound whereas, postoperatively, partial coherence interferometry was used. No cases of late ectasia were identified in the patients of the present study, maybe because all patients underwent a careful preoperative corneal topographic examination, and those with abnormal patterns were excluded, albeit with first-generation Placido disc systems. Another less likely explanation could be that some cases of ectasia have been lost.

Higher-order aberration analysis was not performed, as this was not performed even 


\section{Spherical Equivalent Refraction Accuracy \\ 85 eyes, 20 years postoperative}

80.00

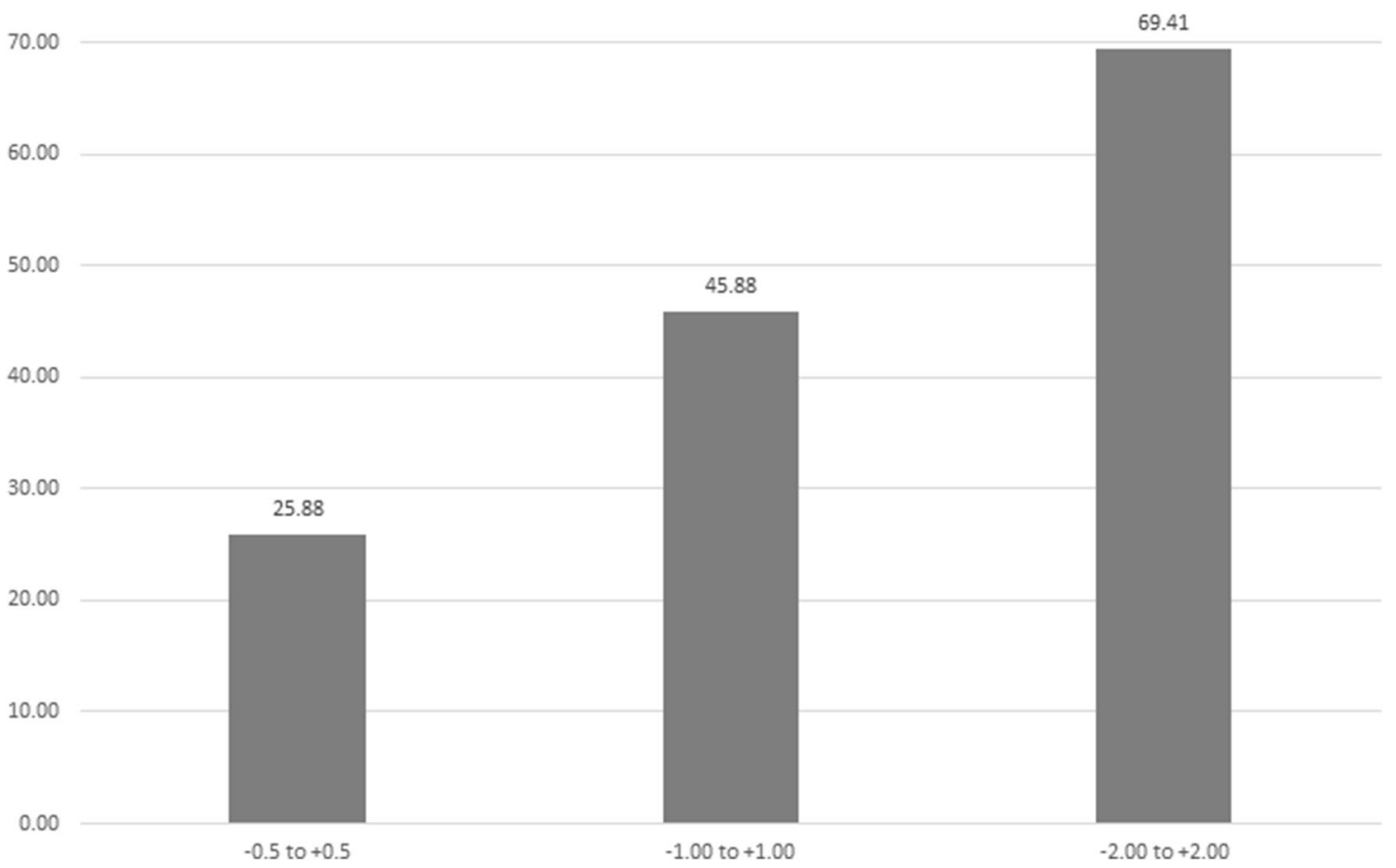

Fig. 5 Spherical equivalent refraction accuracy in different ranges of achieved correction at 20-year follow-up

Table 1 Number and percentage of eyes in the different ranges of achieved correction, with safety and efficacy indices for each group

\begin{tabular}{|c|c|c|c|c|c|c|}
\hline & \multicolumn{2}{|c|}{$\begin{array}{l}\text { Total }(85 \\
\text { eyes) }\end{array}$} & \multicolumn{2}{|c|}{$\begin{array}{l}\leq 6 \mathrm{D}(54 \\
\text { eyes })\end{array}$} & \multicolumn{2}{|c|}{$\begin{array}{l}>6 \mathrm{D}(31 \\
\text { eyes) }\end{array}$} \\
\hline & Eyes & $\%$ & Eyes & $\%$ & $\overline{\text { Eyes }}$ & $\%$ \\
\hline \pm 0.50 & 22 & 25.9 & 18 & 33.3 & 4 & 12.5 \\
\hline \pm 1.00 & 39 & 45.9 & 32 & 59.3 & 7 & 21.9 \\
\hline \pm 2.00 & 59 & 69.4 & 46 & 85.2 & 13 & 40.6 \\
\hline Safety index & 1.00 & & 1.00 & & 1.01 & \\
\hline Efficacy index & 0.63 & & 0.76 & & 0.37 & \\
\hline
\end{tabular}

preoperatively, so no conclusion can be made. Moreover, over the years, the machine was upgraded, with the introduction of the TTZ; although comparison between the two groups could have been of some interest, unfortunately only three eyes were treated without TTZ, so the number of eyes was insufficient to make this comparison.

We are aware that, in this study, there are some limitations. Firstly, modern laser devices are better than those utilized 20 years ago, making us suppose that the results of treatment performed today would be better. Another limitation could be that intermediate follow-up evaluations are missing, and there was a large percentage of follow-up loss. Furthermore, in some cases, more than one eye per patient was selected, but in those years, most of the treated eyes were anisometropic, so this limitation could be less important. It could be argued that in studies with such a long follow-up, the sample size may be affected by noise or bias originating from changes in the materials, personnel, and standards used to perform the 
Table 2 Summary of previous articles on long-term follow-up of PRK

\begin{tabular}{|c|c|c|c|c|c|c|}
\hline Study & $\begin{array}{l}\text { Length of } \\
\text { follow-up } \\
\text { (years) }\end{array}$ & No. patients/No. eyes & $\begin{array}{l}\text { Preoperative } \\
\text { mean SE } \\
\text { (D) } \pm \text { SD }\end{array}$ & $\begin{array}{l}\text { Postoperative } \\
\text { mean SE } \\
\text { (D) } \pm \text { SD }\end{array}$ & $\begin{array}{l}\text { Efficacy } \\
\text { index }\end{array}$ & $\begin{array}{l}\text { Safety } \\
\text { index }\end{array}$ \\
\hline $\begin{array}{l}\text { Cennamo et al. } \\
\text { (current } \\
\text { study) }\end{array}$ & 20 & $54 / 85$ & $-5.90 \pm 3.56$ & $-1.60 \pm 2.10$ & 0.63 & 1.00 \\
\hline Wagh et al. [8] & 18 & $25 / 45$ & $+4.11 \pm 1.82$ & $+1.13 \pm 1.84$ & 0.47 & 0.83 \\
\hline Shalchi et al. [9] & 18 & $46 / 46$ & $-4.86 \pm 1.61$ & $-0.74 \pm 1.40$ & 0.58 & 0.998 \\
\hline $\begin{array}{l}\text { Vestergaard et al. } \\
\quad[10]\end{array}$ & $13-19$ & $160 / 160$ & $-4.84 \pm 2.95$ & $-1.00 \pm 1.56$ & $\begin{array}{l}\text { Not } \\
\quad \text { reported }\end{array}$ & $\begin{array}{l}\text { Not } \\
\text { reported }\end{array}$ \\
\hline $\begin{array}{l}\text { Lombardo et al. } \\
\qquad[11]\end{array}$ & 8 & $\begin{array}{l}\text { 33/66 divided into } 3 \text { groups: low and } \\
\text { high myopia and astigmatism }\end{array}$ & $\begin{array}{l}\text { Low: } \\
\qquad-2.82 \pm 0.86 \\
\text { High: } \\
\quad-6.30 \pm 1.27 \\
\text { Astigmatism: } \\
\quad-3.03 \pm 2.09\end{array}$ & $\begin{array}{l}\text { Low: } \\
\qquad-0.28 \pm 0.16 \\
\text { High: } \\
\quad-0.56 \pm 0.57 \\
\text { Astigmatism: } \\
\quad-0.48 \pm 0.70\end{array}$ & $\begin{array}{l}\text { Not } \\
\quad \text { reported }\end{array}$ & $\begin{array}{l}\text { Not } \\
\text { reported }\end{array}$ \\
\hline Dirani et al. [13] & $2-13$ & $125 / 125$ & $-4.05 \pm 1.17$ & $-0.64 \pm 0.83$ & $\begin{array}{l}\text { Not } \\
\quad \text { reported }\end{array}$ & $\begin{array}{l}\text { Not } \\
\text { reported }\end{array}$ \\
\hline Shojaei et al. [14] & 8 & $\begin{array}{l}107 / 194 \\
\text { Divided into } 3 \text { groups: low, moderate, } \\
\text { and high myopia }\end{array}$ & $\begin{array}{l}\text { Low: } \\
\quad-4.00 \pm 1.84 \\
\text { Moderate: } \\
\quad-6.80 \pm 1.74 \\
\text { High: } \\
\quad-11.00 \pm 3.74\end{array}$ & $\begin{array}{l}\text { Low: } \\
\quad-0.23 \pm 0.19 \\
\text { Moderate: } \\
\quad-0.84 \pm 0.48 \\
\text { High: } \\
\quad-1.21 \pm 0.95\end{array}$ & $\begin{array}{l}\text { Not } \\
\quad \text { reported }\end{array}$ & $\begin{array}{l}\text { Not } \\
\text { reported }\end{array}$ \\
\hline Alió et al. [15] & 10 & $191 / 267$ & $-8.87 \pm 2.25$ & $-0.60 \pm 1.47$ & 0.82 & 1.09 \\
\hline Alió et al. [16] & 10 & $138 / 225$ & $-3.81 \pm 1.29$ & $-0.10 \pm 0.80$ & 0.82 & 1.04 \\
\hline Rajan et al. [17] & 12 & $68 / 68$ & $-4.06 \pm 1.73$ & $\begin{array}{l}\text { Divided into } 6 \\
\text { groups: } \\
\text { 2 D: } \\
\quad-0.30 \pm 1.00 \\
\text { 3 D: } \\
\quad-1.03 \pm 0.60 \\
4 \mathrm{D}: \\
-2.30 \pm 1.40 \\
5 \mathrm{D}: \\
-2.50 \pm 1.10 \\
6 \mathrm{D}: \\
-3.15 \pm 2.07 \\
7 \mathrm{D}: \\
-4.47 \pm 1.60\end{array}$ & $\begin{array}{l}\text { Not } \\
\quad \text { reported }\end{array}$ & $\begin{array}{l}\text { Not } \\
\text { reported }\end{array}$ \\
\hline $\begin{array}{l}\text { O'Brart et al. } \\
{[18]}\end{array}$ & 20 & $42 / 42$ & $-5.13 \pm 1.86$ & $-1.72 \pm 1.69$ & 0.49 & 0.97 \\
\hline
\end{tabular}

$S E$ spherical equivalent, $S D$ Standard deviation 
tests. However, in the present study, the personnel and the device used to test the visual acuity were the same.

\section{CONCLUSIONS}

Our study confirms that PRK could be considered a safe procedure, with no long-term sightthreatening complications such as late ectasia or haze, even utilizing old devices.

\section{ACKNOWLEDGEMENTS}

Funding. This study was funded by a FARB grant from University of Salerno. The Rapid Service Fee was funded by the authors.

Authorship. All named authors meet the International Committee of Medical Journal Editors (ICMJE) criteria for authorship for this article, take responsibility for the integrity of the work as a whole, and have given their approval for this version to be published.

Disclosures. Giovanni Cennamo, Feliciana Menna, Fabrizio Sinisi, Gilda Cennamo, Maria Angelica Breve, Pasquale Napolitano, Maddalena De Bernardo, Livio Vitiello and Nicola Rosa declare that they have no conflict of interest.

Compliance with Ethics Guidelines. The study protocol was consistent with the tenets of the Declaration of Helsinki and institutional review board approval was obtained (Cometico Campania Sud, Italy), together with informed consent from each patient, where all patients were informed that their data could have been used for potential studies.

Data Availability. The datasets generated during and/or analyzed during the current study are available from the corresponding author on reasonable request.

Open Access. This article is licensed under a Creative Commons Attribution-NonCommercial
4.0 International License, which permits any noncommercial use, sharing, adaptation, distribution and reproduction in any medium or format, as long as you give appropriate credit to the original author(s) and the source, provide a link to the Creative Commons licence, and indicate if changes were made. The images or other third party material in this article are included in the article's Creative Commons licence, unless indicated otherwise in a credit line to the material. If material is not included in the article's Creative Commons licence and your intended use is not permitted by statutory regulation or exceeds the permitted use, you will need to obtain permission directly from the copyright holder. To view a copy of this licence, visit http://creativecommons.org/ licenses/by-nc/4.0/.

\section{REFERENCES}

1. Marshall J, Trokel S, Rothery S, Schubert H. An ultrastructural study of corneal incisions induced by an excimer laser at $193 \mathrm{~nm}$. Ophthalmology. 1985;92:749-58.

2. Munnerlyn CR, Koons SJ, Marshall J. Photorefractive keratectomy: a technique for laser refractive surgery. J Cataract Refract Surg. 1988;14:46-52.

3. McDonald MB, Frantz JM, Klyce SD, et al. One-year refractive results of central photorefractive keratectomy for myopia in the nonhuman primate cornea. Arch Ophthalmol. 1990;108:40-7.

4. Seiler T, Kahle G, Kriegerowski M, Wollensak J. Laser keratomileusis for correction of myopia. Fortschr Ophthalmol. 1990;87:479-83.

5. McDonald MB, Frantz JM, Klyce SD, et al. Central photorefractive keratectomy for myopia: the blind eye study. Arch Ophthalmol. 1990;108:799-808.

6. Gartry DS, Kerr Muir MG, Marshall J. Photorefractive keratectomy with an argon fluoride excimer laser: a clinical study. Refract Corneal Surg. 1991;7: 420-35.

7. Cennamo G, Rosa N, Breve MA, Di Grazia M. Technical improvements in photorefractive keratectomy for correction of high myopia. J Refract Surg. 2003;19:438-42. 
8. Wagh VK, Dave R, O'Brart DP, et al. Eighteen-year follow-up of hyperopic photorefractive keratectomy. J Cataract Refract Surg. 2016;42:258-66.

9. Shalchi Z, O'Brart DP, McDonald RJ, Patel P, Archer TJ, Marshall J. Eighteen-year follow-up of excimer laser photorefractive keratectomy. J Cataract Refract Surg. 2015;41:23-322.

10. Vestergaard AH, Hjortdal JØ, Ivarsen A, Work K, Grauslund J, Sjølie AK. Long-term outcomes of photorefractive keratectomy for low to high myopia: 13 to 19 years of follow-up. J Refract Surg. 2013;29:312-9.

11. Lombardo M, Lombardo G, Ducoli P, Serrao S. Long-term changes of the anterior corneal topography after photorefractive keratectomy for myopia and myopic astigmatism. Invest Ophthalmol Vis Sci. 2011;52:6994-7000.

12. Chen L, Ye T, Yang X. Evaluation of the long-term effects of photorefractive keratectomy correction for myopia in China. Eur J Ophthalmol. 2011;21: 355-62.

13. Dirani M, Couper T, Yau J, et al. Long-term refractive outcomes and stability after excimer laser surgery for myopia. J Cataract Refract Surg. 2010;36: 1709-17.

14. Shojaei A, Mohammad-Rabei H, Eslani M, Elahi B, Noorizadeh F. Long-term evaluation of complications and results of photorefractive keratectomy in myopia: an 8-year follow-up. Cornea. 2009;28: 304-10.

15. Alió JL, Muftuoglu O, Ortiz D, et al. Ten-year follow-up of photorefractive keratectomy for myopia of more than -6 diopters. Am J Ophthalmol. 2008;145:37-45.

16. Alió JL, Muftuoglu O, Ortiz D, et al. Ten-year follow-up of photorefractive keratectomy for myopia of less than -6 diopters. Am J Ophthalmol. 2008;145:29-36.

17. Rajan MS, Jaycock P, O'Brart D, Nystrom HH, Marshall J. A long-term study of photorefractive keratectomy; 12-year follow-up. Ophthalmology. 2004;111:1813-24.

18. O'Brart DP, Shalchi Z, McDonald RJ, Patel P, Archer TJ, Marshall J. Twenty-year follow-up of a randomized prospective clinical trial of excimer laser photorefractive keratectomy. Am J Ophthalmol. 2014;158:651-63.

19. Dausch D, Klein R, Schroder E, Dausch B. Excimer laser photorefractive keratectomy with tapered transition zone for high myopia. A preliminary report of six cases. J Cataract Refract Surg. 1993;19: 590-4.

20. Rosa N, Cennamo G, Pasquariello A, Maffulli F, Sebastiani A. Refractive outcome and corneal topographic studies after Photorefractive keratectomy with different-sized ablation zones. Ophthalmology. 1996;103:1130-8.

21. De Bernardo M, Zeppa L, Cennamo M, Iaccarino S, Zeppa L, Rosa N. Prevalence of corneal astigmatism before cataract surgery in Caucasian patients. Eur J Ophthalmol. 2014;24:494-500.

22. De Bernardo M, Zeppa L, Zeppa L, Cornetta P, Vitiello L, Rosa N. Biometric parameters and corneal astigmatism: differences between male and female eyes. Clin Ophthalmol. 2020;14:571-80.

23. Ivarsen A, Hjortdal J. Seven-year changes in corneal power and aberrations after PRK or LASIK. Invest Ophthalmol Vis Sci. 2012;53:6011-6.

24. De Bernardo M, Capasso L, Caliendo L, Paolercio F, Rosa N. IOL power calculation after corneal refractive surgery. Biomed Res Int. 2014;2014:658350.

25. De Bernardo M, Rosa N. Central corneal thickness after cross-linking using high-definition optical coherence tomography, ultrasound, and dual Scheimpflug tomography: a comparative study over one year. Am J Ophthalmol. 2017;176:254.

26. De Bernardo M, Salerno G, Cornetta P, Rosa N. Axial length shortening after cataract surgery: new approach to solve the question. Transl Vis Sci Technol. 2018;7:34. 